\section{TWO VELOCITIES OF SOUND IN HELIUM-II}

A CONSEQUENCE of the theory put forward in 1941 by the Soviet physicist, Landau, to explain the peculiar flow-properties of liquid helium ${ }^{1}$ was the co-existence of two speeds of sound in this medium. Prof. E. N. da C. Andrade, in his recent account ${ }^{2}$ of contemporary physical research in the U.S.S.R., stated that Peshkov had succeeded in demonstrating that a 'second' sound did actually occur in helium-II. A paper giving details of the theoretical background and the experimental technique used was delivered earlier in 1945 by E. M. Lifshits and V. P. Peshkov before a gathering of the Physico-Mathematical Section of the Academy of Sciences of the U.S.S.R., and a summary of the work appears in an issue of the Academy's Herald, which has recently been received ${ }^{3}$.

According to Landau's theory, liquid helium at temperatures below the $\lambda$-point, $2 \cdot 19^{\circ} \mathrm{K}$., is a 'mixture' of two types of helium, superfluid and normal, which differ in their rates of flow. On this basis he was able to give an explanation of most of the known flow-properties of helium-II and to indicate a way in which the theory might be tested. An application of the hydrodynamic equations to the study of the propagation of sound in superfluid helium showed that there ought to occur, in addition to the 'primary' sound wave, a wave of another type ('secondary') which would be peculiar to helium-II. The primary wave corresponds with normal sound waves; it is propagated at $240 \mathrm{~m}$. per sec. and the speed is nearly independent of the temperature. The speed of the secondary wave should change rapidly with temperature and be nil at the transition point. According to Lifshits's analysis, the primary wave occurs when the particles of superfluid and normal helium in any given element of volume vibrate so that the liquid moves as a whole; the secondary, when there is relative movement between the particles, governed by the principle that the centre of gravity of each element remains stationary. In the latter case the amplitude of pressure oscillation is small and the effect of temperature is great ; the reverse applies to the primary wave.

This picture made it necessary to suppose that all the usual methods of exciting sound waves would produce only the one primary type of sound in liquid helium-II. A special method employing temperature variations instead of pressure variations was required. This was found in the vibrations of a solid surface, the temperature of which could be made to change periodically with time. A thermal oscillator was designed by Peshkov so that, theoretically, only the secondary sound wave should be radiated.

A glass tube, $2 \mathrm{~cm}$. in diameter and $25 \mathrm{~cm}$. long, was placed in liquid helium. The bottom of the tube was closed with a flat glass disk and the other end was left open. Through this end was pushed a flat cylindrical piston with a heater of very thin constantan wire wound on the end of it. There was a small opening in the middle of the piston through which a small thin-walled steel tube could move. At the end of this tube was fixed a small ivory bobbin on which a resistance thermometer of extremely thin phosphor-bronze wire was wound. The electrical resistance of phosphor-bronze changes rapidly with temperature at the temperatures of liquid helium; hence, if the temperature of the helium is made to change periodically and the wire of the thermometer is sufficiently thin to reflect the temperature changes in the helium, then the resistance of the thermometer must also change periodically. When a continuous current is passed through the thermometer, the voltage drop will be proportional to the resistance and it will follow the change of temperature of the helium. It was found, however, that the voltage variations were very small and that they had to be amplified a million times before they could be examined on a cathode ray oscillograph.

On the passage of an alternating current through the heater on the end of the piston, thermal waves of double the frequency were produced. These waves were taken up by the helium, passed to the bottom of the tube, were reflected back to the piston, were reflected again and so on. If the distance between the piston and the bottom of the tube was not equal to a whole number of half-waves, then the phases of the various waves were different and no temperature oscillation was observed at all. If a whole number of half-waves could be packed into this distance, then resonance occurred, standing waves were produced, and a periodic temperature change was indicated on the cathode ray oscillograph.

By changing the position of the thermometer in the tube, it was found possible to measure the length of the waves and, consequently, with a known frequency, to determine the speed of propagation of the thermal vibration. It was thus discovered that the speed increases from $19 \cdot 5 \mathrm{~mm}$. per sec. at $1 \cdot 35^{\circ} \mathrm{K}$. to $20.4 \mathrm{~m}$. per sec. at $1.65^{\circ} \mathrm{K}$. and then rapidly falls, becoming nil at the $\lambda$-point $\left(2 \cdot 19^{\circ} \mathrm{K}\right.$.). At these temperatures normal sound travels at about $250 \mathrm{~m}$. per sec. It is stated that within the frequency-range of 100-10,000 cycles per second, a 'dispersion' of speed was not observed.

The experimentally determined values for the speed of the 'second' sound do not agree exactly with those predicted by Lifshits; but it is considered probable that the experimental data upon which the calculations were made were inaccurate. In any event, the results of the work provide a remarkable confirmation of Landau's theory.

G. Stanley Smrth.

1 See Smith, G. S., Nature, 155, 598 (1945).

Andrade, E. N. da C., Nature, 158, 223 (1945).

'Vestnik Akademii Nauk, No. 4, 117 (1945).

\section{SOCIAL SURVEY OF KITCHENER- WATERLOO, ONTARIO}

$T N$ the early part of 1944 the Canadian Chamber of Commerce sponsored a community fact-finding survey in the twin towns of Kitchener-Waterloo, Ontario. Its purpose was "to find out just what changes had resulted from four and a half years of war, to discover what were the expectations of municipal authorities and business men as to their own post-war needs and opportunities, and to search out and assemble the plans of individuals for themselves and their families". Public interest was enlisted, and the survey met with overwhelming public support. The British Government's Social Survey has a similar experience of public sympathy with surveys, although that organisation has not had the benefit of widespread explanation of its purposes and methods.

In most countries, hitherto, economic intelligence has been for the main part based on national and 
industrial production and trading totals. However, parallel with the development of national statistics for purposes of war control, there has been the increasing use of the social survey technique and sampling to provide administrators with the social data necessary for efficient handling of the home front.

The recent Government White Paper on Full Employment indicated that "everything possible must be done to limit dangerous swings in expenditure on private investment". It was further pointed out that "demand may outrun supply and create inflationary rise in prices . . . and ... civilian production when it is resumed may concentrate on the wrong things from the point of view of national needs. Government action will be directed to forestall, so far as is possible, each of these dangers." It is clear, then, that a method which provides reasonably accurate information about the possible flow of consumers' expenditure could be of great assistance to those responsible for the kind of administrative measures outlined in the White Paper.

In consumer surveys of this sort, based on questionnaires, the technical points which need most careful attention are the selection of the samples, the construction of the questionnaire and the skill of the investigators in securing the co-operation of the informants.

Different methods of selecting the sample in the Kitchener-Waterloo survey were used for the city, village and farm households, and from the varying success achieved it would appear that the level of organization reached in the collection of these samples varied also. Thus 20 per cent of all farms in the area had schedules sent to them by post, and the report says "this was in order to ensure that there would be sufficient usable returns received from which to select the three farms per school section required". It is doubtful whether this kind of post facto weighting could overcome the bias due to the fact that farmers represented in the final sample would be drawn only from those completing and returning the schedules. On the other hand, the city households were personally canvassed by volunteer workers who, however, were selected as "capable, responsible people able to understand and explain the purpose of the survey and the individual questions to the householder". There was careful instruction of these cenvassers before the work began by experienced investigators, and emphasis was laid on the approach, manner and conduct of an interview. The sample was carefully watched and controlled at all stages.

It appears from the report that the authors hope that "the collection of similar information regarding many samples will increase cumulatively the trustworthiness of the conclusions to be drawn from them, for such conclusions will be derived from a steadily growing mass of data, covering an increasing proportion of the Dominion". Such a process may lead to misleading results. The Kitchener-Waterloo area was chosen for this initial study "not primarily because of its business characteristics but because it was believed that both Boards of Trade would respond favourably to such an invitation . . . make the necessary preparations and complete the task". An accumulation of data from districts which are chosen in this way, or which decide for their own reasons to carry out surveys, may be of interest in itself but will be unlikely to provide data representative of the whole country.

The information sought from these different sections of the community varied in the detail required.
Householders were asked to estimate their purchases of items on a printed list of household goods in the first year after the War. The farmers were asked to state the size of livestocks and different crop acreages for 1939 and 1944 and to estimate relevant figures for the first post-war year. In addition to this, farmers were asked to estimate their post-war expenditure on farm buildings and equipment. On the other hand, the business men were asked only to estimate tho post-war expenditure on buildings and equipment, the staff to be employed and the estimated pay-roll for the first post-war year.

It seems important to question the basis for these business estimates. Past experience indicates that estimates by business people of the future levels of business activity may err considerably, and planned expenditures on capital equipment are likely to be thrown overboard when they conflict with market conditions. Some kind of check on the basis of the business expenditure estimate would therefore seem desirable. On the household schedules rather more care was taken over this point. The question put to informants "provides a typical list of things which people normally buy, but have done without during the war, and asks which they plan to buy after the war. Only those articles definitely planned for should be stated, not all those things which it would be nice to have." The value of this household expenditures information is greatly enhanced by questions asking how each item in the projection expenditure is to be financed, whether from current income, cash or other savings, instalment credit or borrowing. From this it is possible to judge to some extent what element of doubt there is in the projected estimates, for clearly much greater weight can be put upon expenditure estimates which are to be financed from current income at the time of the projected expenditure.

What is the picture which emerges from the survey? In the area studied, the information gathered shows that the labour force rose by about 34 per cent between 1939 and 1943, although no fewer than one quarter of that 1939 force had enlisted. This shows quite simply the dimensions of the full-employment problem in the area. Secondly, on the basis of estimates of post-war sales, and taking into account people returning from the Services, there is a small prospective excess of jobs over available labour.

An interesting comment on this later finding is made in the report: "Over all, the manufacturing industries expect a decline of about $1 \frac{1}{2} \%$ on sales and in the number of employees, but they look for an aggregate reduction in factory payrolls of slightly more than $26 \%$ ". On the other hand: "The somewhat sketchy statistics of present and anticipated household incomes suggest that citizens themselves expect their post-war incomes to be within $1 \%$ or $2 \%$ of their present incomes".

This is a most important discrepancy to have unveiled. Clearly if pay-rolls are to be what the business houses expect, then post-war consumers purchases will need to be curtailed, and this means that producers' expected sales will not be made. If the Kitchener-Waterloo survey had shown nothing else, this one finding would in itself have pointed to the most critical stage of any post-war employment policy.

Another interesting finding is that consumers plan to spend almost ten times as much on housing as the Kitchener-Waterloo building firms estimate as the total of their post-war business. Nearly half the total expenditure envisaged is to be on buildings and con- 
struction. The difference between consumers estimates and the estimates of business men in this matter arouses a certain amount of scepticism about the estimates of business men on which other conclusions in the report are based. One wonders, for example, how consumers estimates of post-war purchases of domestic appliances, motor-cars or furniture would have compared with the business estimates of sales for these commodities had the business schedules asked for sufficient detail of this sort.

The Kitchener-Waterloo survey is based on the assumption that the end of the War will see a return to the operation of consumers demand in a conapletely uncontrolled economy. So far as Great Britain is concerned, at any rate, it is doubtful if such conditions will prevail during the immediate post-war years. It has been said that "the guiding principle with regard to the production and distribution of consumption goods, will be to secure, so far as possible, that labour and capacity no longer needed for munition production shall be used for producing civilian goods of high priority-until the primary needs are met, resources which could be applied to meet them should not be diverted to the production of luxuries for home consumption".

This will need detailed information about stocks and needs. Much war-time administrative action has been based on such detailed information of basic needs. Information collected on a national scale would complement the regular censuses of production and national income and expenditure accounts which are promised, and would, in a short time, provide a sufficient body of data on buying habits to act as a complete check on the consumers' estimates.

There will be inevitably many successors to this survey. It is a useful job well done, and future workers in this field will certainly benefit from careful study of the methods used and the results.

(The survey has not so far been put on sale to the public, but the Canadian Chamber of Commerce has made some copies available to interested bodies.)

L. Moss.

\section{SCIENCE IN CANADA AND SOUTH AFRICA}

$\mathrm{T}$ HE third of a series of discussions on the organisation of scientific research in the British Commonwealth, arranged by the Society for Visiting Scientists, was held at the Society's House at 5 Old Burlington Street, London, on January 9, with Dr. C. S. Hanes, director of the Food Investigation Department, Department of Scientific and Industrial Research, in the chair. The speakers were: Dr. W. E. van Heyningen, assistant director of the Wellcome Physiological Research Laboratory ; Major E. Boden, Council for Scientific and Industrial Research, Canada; Dr. R. Y. Stanier ; Dr. J. G. Malloch, chief scientific liaison officer for Canada; Dr. W. Cullen; Colonel J. H. de Boer, deputy chief of staff, Netherlands Military Administration; Colonel Marquad, head of Army Education Services in South Africa; and Colonel O. M. Solandt, director of Scientific Defence, Canada.

Canada, being the oldest Dominion, also enjoys the most elaborate research organisation. As its primary and oldest industry is agriculture, it was in that field that research was first applied. Dr. William Sanders and Sir Charles Sanders were jointly responsible for the discovery of a new variety of wheat which revolutionized agriculture in North America. This encouraged the Department of Agriculture to estab. lish a vast research organisation with experimental stations all over the country, and special laboratories covering every branch of agricultural science. One of its latest successes has been the reduction of loss from wheat rust. The Department of Mines and Resources deals with the exploitation of natural resources, including sylviculture, forest products, timber utilization as well as minerals. There is a strong Fisheries Research Board, and a Grain Research Laboratory under the Department of Trade and Commerce.

The National Research Council was not established until 1915. Since then, it has achieved, through a system of associated committees, a large measure of co-ordination between different institutions in the country, which has been very valuable, among other things, in mobilizing Canada's scientific resources for war purposes.

However, Canada has a serious problem in the loss of so many of its scientific men, mainly to the United States. The question of the isolation of scientific workers, which has been stressed in all the former discussions on other regions of the Commonwealth, is also a problem in Canada, particularly in the west, and here their southward drift is a natural but undesirable result. The remedy is to improve the conditions of scientific research in Canada and to enlarge university staffs, thereby not only reducing the individual teaching load, but also opening up new fields of teaching and research such as genetics, microbiology, biochemistry, oceanography, etc. Industrial research has so far been relatively neglected in Canada, since all the larger companies are subsidiaries of American firms, and research work is done in the United States for them; but it should now be actively developed.

The problems of Canada are rather different from those of the other Dominions, since it will clearly be necessary to integrate and co-ordinate its scientific activities with those of the United States to at least as great an extent as with those of the rest of the Commonwealth.

South Africa was first colonized by Dutch farmers when the Dutch East India Company established stations to provide fresh food and supplies for the crews of its ships. They were joined by French Huguenots, and after the British took over in 1806 , by British immigrants, following the Industrial Revolution. Early British rule was unenlightened. and caused a split in the population which endures to this day. The discovery of diamonds and gold, which created a boom, set mining as the second main facet of South African life, the first being agriculture. The population to-day is ten million people. The Africans outnumber the whites by four to one, and the 20 per cent of poor whites among the Europeans constitute a special problem. Only about one fifth of the total population have attained what may be regarded as a minimum standard of life. To raise this level, the production of the country must be raised.

Agriculture, though fairly self-supporting and occupying two thirds of the population, only utilizes 6 per cent of the land surface. This is due to several reasons: bad farming habits, dry soil, excessive evaporation, irregular rains. Moreover, Schwartz has produced evidence in favour of the view that the dryness of South Africa has progressively increased owing to the diversion of great rivers from large 